\title{
Introduction: knowledge, innovation systems and the role of power
}

\section{Blandine Laperche, Dimitri Uzunidis and Nick von Tunzelmann}

Knowledge and innovation are the two main resources of contemporary capitalism. To study and understand these roles, it is first helpful to draw on the theory of systems. Technological innovation cannot be understood when isolated from its context. Putting innovation in perspective requires a holistic and systemic approach: new technologies, new products, but also new markets, new organization and new management practices. The authors in this volume stress the importance of cognitive and social linkages, as well as the role of 'communities of practice' in the assessment and analysis of innovation within the enterprise, local and national economies and at the international level. The approach of scholars as well as practitioners should be directed toward the economic and social impacts of innovation activities.

The authors here perform a series of studies at different levels (research labs, enterprises and networks) and throughout systems of innovation and innovative milieux based upon practical cases, to present emerging ideas from established theoretical developments of economists, historians and geographers. Indeed, the genesis of knowledge and its diffusion (information) depends upon the density of the relationships among individuals and organizations at both micro-economic and macro-economic levels. What may be concluded from the analysis is that some specific actors (the state, enterprises) determine separately but also jointly, the process of diffusion, coordination and standardization of knowledge and technologies. Institutional and entrepreneurial networks play a fundamental role (vis-àvis the employee or the entrepreneur) in the explanation of the systemic nature and the dynamics of innovation within contemporary capitalism. Cognitive relations between the actors of innovation show that the issue of appropriation of knowledge is as important as the production of new knowledge for the genesis of innovation.

The permanent innovation strategy of the enterprise needs continuous flows of scientific and technological inputs. Externalities and agglomeration 
effects are two phenomena associated with location that must be taken into account in the constitution and constant renewal of the enterprise's scientific and technological potential. Location choice is a precursor to the reinforcement of the firm's innovation capacities, allowing it to reach new markets and to penetrate complex networks (enterprises, research centres, other institutions). These networks constitute pools of resources for large enterprises and are seen as an essential tool for the creation of new innovative businesses and for regional development.

The growing link between knowledge and markets can be considered as symbolic of the current socialization of production forces. The systemic approach is today highly relevant because of this socialization. The need is for constantly renewing products, services and production methods, and this increases the cost and risk of knowledge development and dissemination. Networks (systemic relations) among an increasing number of institutions (firms of different size, public and private research labs) are thus becoming obligatory for those who want to remain competitive. Innovative milieux thus become one of the key features of present-day systems that are developed throughout the book, and most explicitly in Part III.

The second key notion that permeates this book is the role of power, both economic and political. The free market economy is based on abstract hypotheses that can be called into question by reality. Starting from the renewal of technologies and markets, the authors in this book clearly show that military programmes and industries constitute one of the engines of capitalist economies, arguably even more than the weight of big firms and the regulatory force of the state. In point of fact, the interactions between the military sector and competitive industries feed innovation systems (at the micro- and macro-economic levels) with new technologies and new organizational methods. Given the importance of military R\&D in the large economies for generating radical innovations, a central role is assigned in Part II of this book to the analysis of the functioning of the systems of military and civil innovation.

However the role of power also exercises itself in more subtle ways, as all of the chapters that follow indicate. Chapter 1 by Stefan Kesting develops McCloskey's notion of the power of persuasion in communication, as independently developed by Boulding out of using communication for conflict resolution (through reconciliation, compromise, etc.), in parallel with the well-known work of Hirschman on 'voice'. As Kesting observes, 'Inspired by Galbraith's book, The Anatomy of Power, Boulding distinguishes basically three forms of power: (1) Political-military, threat, or destructive power; (2) Economic, exchange, or productive power; and (3) Social, love, or integrative power.' Boulding defines the third of these as 'the power to 
be accepted, respected, legitimated, loved, and to form part of a larger network'. In practice it can involve social exclusion as well as consensus and inclusion. The argument is clarified further through reference to Myrdal's notion of cumulative circular causation and Habermas' concept of communicative action, and the ways in which the latter transforms into communicative power, as well as Galbraith's 'conditioned power' and 'countervailing power'. These ideas are shown to underpin familiar concepts from the literature on innovation such as routines (Nelson and Winter), scripts (Nooteboom), leadership (Witt), 'ba' space (Nonaka and Konno), learning by interacting (Lundvall), etc.

Chapter 2, by Marie-Pierre Bès, has as its objective '. . . to demonstrate that knowledge being developed in laboratories is also the object of conflicts concerning its sharing, development and publication between public sector teams and their industrial partners.' This draws on the postulate that '. . . tacit knowledge acquired in scientific laboratories is not "visible" and identifiable except during activities involving strong interpersonal relationships'.

Research networks of the kind studied in this chapter fall into the category of 'emerging networks that are formed within projects where neither the partners nor the contents are stabilized - the knowledge is local, competing, appropriable, specific and non-substitutable' rather than those that 'are consolidated, dominated by routine activities and groups of stabilized members'. The author studies the issues surrounding the difficulty of appropriating knowledge (intellectual property rights, or IPR) in such contexts, and the arrangements resorted to in order to permit communication, with special reference to joint public-private laboratories in France. These do not limit themselves to internal interaction but have to remain flexible in relation to other networks, both national and international.

The issue of proprietary versus open-access knowledge is taken further in Chapter 3, by Marc Isabelle. The author's survey shows the conflicts in scientific communication arising out of a heightened emphasis on IPRs in public research organizations (PROs) anxious to patent their activities conflicts between organizations and even within laboratories. About twothirds of the respondents to the survey ('research directors' of a leading French PRO) are able to undertake both proprietary and open-access research.

Chapter 4, by Alfredo Ilardi and Blandine Laperche, examines the progress made towards an integrated patent system in Europe. Patents symbolize the well-known adage that 'knowledge is power'. Attempts to harmonize IPRs in Europe have been continuing for more than a century and are linked to patterns of globalization. Conflicts of interest have continually 
slowed such attempts, despite the resort to political action to overcome them. The chapter concludes by expressing the view that supportive political actions should be enhanced at the European level.

As already noted, Part II of the book (Chapters 5 to 7) deals overtly with military power, and since it is discussed at length below we pass on here to Part III, where communication and relational issues return via innovative milieux and clusters, in which the balance between networks and power relations becomes analytically more complex. Dimitri Uzunidis in Chapter 8 defines a network as 'a system whose purpose is to achieve integrated production (often multiple) in a single value chain and under the direction or coordination of holding or central firms'. Others however consider 'pure' networks as relationships - particularly for the interchange of knowledge in which both market and hierarchy relationships are absent. In practice, such 'pure' networks are rare in the commercial and industrial world, where markets, hierarchies and networks tend to be interconnected and overlapping, in ways that have yet to be fully defined in the analytical literature. Uzunidis' chapter assesses the role of the individual enterprise in terms of the balance between investing in its local environment (the innovative milieu) and drawing upon it, as a potential arena for conflict and indeed conflict resolution.

For Schumpeter, 'The entrepreneur is prompted by a desire for power'. In Chapter 9, Sophie Boutillier, Blandine Laperche and Dimitri Uzunidis carry forward this idea into asking what constrains the emergence of entrepreneurial actions, and why the role does not endure. In their view the heroic entrepreneur of Schumpeter has become a 'socialized entrepreneur' in a context of networked capitalism. In this respect the entrepreneur has not really disappeared, but his/her power structures have altered considerably - knowledge plus finance and connections dictate the emergence of the power of the entrepreneur, but other and more pragmatic elements also become important in preserving that power.

Examples of such elements are evident in Chapter 10, by Kavoos Mohannak and Robyn Keast, on science parks, a format that in many parts of the world has failed to deliver its promises. In the case they study, of the Brisbane Technology Park in Australia, they found that the structures in place give rather too much emphasis to developing internalized cooperative networks, whereas they found more need to establish external linkages. A new balance may have to be struck between maintaining strong ties and facilitating weak ties (in the sense of Granovetter).

Finally, Chapter 11, by Paul Sommers, on the life sciences cluster in the Seattle (Washington state) area of the USA, assesses the role of power asymmetries in the 'cluster', in respect of the relationships between large pharmaceutical companies ('big pharma') and small biotechnology labs, 
universities, non-profit organizations and government and venture-capital funds in this region. Formal associations and partnerships (such as the 'Prosperity Partnership') have done a great deal to integrate activities and diverse agents that could have been little more than a local 'clump' into a properly constituted 'cluster'. The state's objective seemingly remains to establish new, powerful integrated corporate hierarchies, but whether or not this will happen is an open question.

\section{PART I: CORE LINKAGES IN THE GENESIS OF INNOVATION: THE KNOWLEDGE DIMENSION}

The first part of the book deals with the core linkages which allow the genesis of innovation. It focuses particularly upon the production, the diffusion and the appropriation of knowledge.

In Chapter 1, Stefan Kesting draws attention to the interaction among individuals that is at the origin of the development of knowledge and innovation. He links communicative action concepts (from Boulding, Habermas, Hirschman, Myrdal) with those of innovation studies (like Schumpeter, Nelson and Winter, Nooteboom, Penrose), in order to show the innovative capacities of communication and its role in the production of new knowledge. The innovative capacities of communication rely on three arguments: information is obtained in conversation, new ideas emerge in dialogues and debates, and institutional change is initiated and implemented on the basis of public disputes. Communication is at the core of the creation, processing and transmission of routines. The innovative capacities of teams are identified as a major resource of the firm. The innovation capacities of networks and clusters are also based on the interaction amongst their members. After an introduction to the model of communicative action, the discussion which follows paves the way towards a communicative theory of innovation.

Communication is particularly important as in today's knowledge-based economy, research relies on collaboration between different types of institutions (notably, from both the public and the private sector). This new context may be a source of advantage (sharing of experience and cost reduction) but it may also result in tensions dealing with the appropriation of shared knowledge. Chapter 2, by Marie-Pierre Bès, deals with cognitive externalities and their flows among research teams. The study is based on a detailed analysis of 133 research contracts signed by the engineering laboratories of the French National Centre of Scientific Research (CNRS) between 1960 and 2000. The author shows how teams can rely upon these different contracts to source a specific form of expertise. More precisely, the 
experimental knowledge available in the labs and in particular their capacity to design and carry out instrumentation experiments is essential although difficult to quantify. Today's types of partnerships such as joint laboratories or technological platforms are a good example of the attempts made to lock up externalities within restricted places.

The question of appropriability of research is also dealt with by Marc Isabelle, whose main objective in Chapter 3 is to provide a typology of research activities connected to the new context of the knowledge-based economy. Public research systems have experienced deep transformations worldwide since the 1980s. In European countries, they are now strongly challenged by the Lisbon strategy of the knowledge economy, a prominent engine of knowledge production and dissemination. Among the changes that are taking place, researchers are prompted to incorporate greater considerations for economic and societal needs into their activities, as well as better protecting their results and working in closer connection with private firms. Some scholars advocate this new social contract for science whereas others express concerns about the pitfalls that may arise from it. In his contribution of detailing 'Pasteur's Quadrant', Donald Stokes had pushed the debate forward by showing that basic research could be use-inspired - and actually was in many cases. Yet, Marc Isabelle argues that Stokes' taxonomy misses a dimension - namely that of proprietary vs. open-access research - which must be taken into account for fully grasping the economics of how the research sector may foster the knowledge economy. The expanded taxonomy allows better identification of the directions in which the pressure for increased relevance of public research really goes and to discriminate among the underlying motivations. The case study of the CEA (Commissariat à l'Energie Atomique) yielded preliminary results concerning this issue and demonstrated that changes have occurred in the way research is conducted, due to the specific nature of the linkage between knowledge and markets.

As networking becomes more pervasive in the course of the current socialization of production, so the need for protection of invention is also growing. Intellectual property rights are incentives and protection tools. In Chapter 4, Alfredo Ilardi and Blandine Laperche retrace the history and evolution of an integrated patent system in Europe and explain this development through the collective and global character of the innovation process in a knowledge-based economy. As the genesis of innovation depends on international - and regional - links between several actors, integrated protection systems are also needed. Ilardi and Laperche also describe the difficulties of harmonization: notably, in the case of the 'Community patent', technical difficulties and the political character of the protection of inventions. To obtain better results in terms of innovation, it 
is necessary, according to these authors, to link the reflection upon patent law harmonization with innovation policies and to transform innovation into a real European political priority.

The first part of the book shows that the new context of the knowledgebased economy has resulted in the tightening up of systemic links between research labs (in either public or private sectors) and the market. Information (communication) and knowledge (appropriation) are the two pillars of the innovation process that mobilize various actors. These new links have offered new opportunities for the production, sharing and dissemination of knowledge, and they also suggest constraints in the relationship to the appropriation of research results.

\section{PART II: MILITARY-BASED INNOVATION NETWORKS}

In Chapter 5, Claude Serfati addresses some issues related to military and commercial technology relations. He puts the debate into a historical context, and emphasizes how dialogues on these relationships have changed over the past six decades, going from 'spin-off' to 'spin-in', then to 'dualtechnologies'. In the mid-1990s it was widely thought that the generalization of dual-use technologies would become a final note in the story of the relationship between military and commercial technologies. However, the Internet case study suggests a more complex relationship between military and commercial dimensions than the usual claim that the Internet 'was invented by the military'. Moreover, the emergence of security issues which are at the core of the globalization process provides a doctrinal framework against which the trajectories of new technologies are emerging, marking a new era in the history of the relationship between military and commercial technologies. It is against this background that, according to Serfati, the new security agenda adopted by the European Union (EU) and the USA must be analysed. This new security agenda combines, in a new and rather unexpected way, military and civilian technologies in some significant sectors (the space sector in the EU, and the biotechnology sector in the USA). Five criteria are relevant for investigating the relations between military and commercial technologies: history, international balance of power between countries, sectors and technologies, entrepreneurship, and contingency.

Within this new context emerges the concept of 'interface structures' that refer to a new type of organization to promote and increase interactions between the different elements of an innovation system, especially between research establishments and potential users of their capabilities. Theses interface structures are studied by Elena Castro-Martínez, Ignacio 
Fernández-de-Lucio and Jordi Molas-Gallart in Chapter 6. The authors identify similarities in the strategies adopted by organizations involved in the transfer of knowledge in two different countries (the UK and Spain) and contexts (university-industry and military-civil sectors). Each is confronted with a common problem: the need to bridge dissimilar organizational cultures and practices. Without any contact among them, these organizations have developed remarkably similar and innovative strategies. Based on their experience, these authors define and characterize the 'interface structure' as a catalyst, increasing the interactions between different types of actors.

Due to the increase of complex linkages between the military and the civil sectors and technologies, it is interesting to study the impacts of different and changing institutional environments upon the firm's knowledge base. In Chapter 7, Michel Callois analyses the case of the defence industry as a specific institutional environment. Based on a sample of 600 observations collected among the best performing defence firms from 1999 to 2005 and their portfolio of patents obtained from the European Patent Office database, Callois argues that the institutional environment shapes the knowledge of defence firms. He proposes a methodological issue to highlight the influence of the institutional context upon patenting behaviour. The trade-off between civilian and military activities is expressed by the relative share of defence income in comparison with the global income of the firm. Econometric tests are run to assess these propositions. They show that the structure of the knowledge base differs depending on the institutional context. Callois concludes that there is a narrow co-evolution between the firm's behaviour and institutional environment. 'Pure' defence firms have a more targeted knowledge base (where capabilities are focused on a few activities) whereas 'mixed' or pure civilian firms have a broader knowledge base.

The second part of the book reveals that the production of military knowledge is more and more embedded in innovation networks that are not specific. This increases the complex character of innovation systems.

\section{PART III: FROM KNOWLEDGE TO MARKET: SYSTEMIC LINKS AT THE LOCAL LEVEL}

In Chapter 8, Dimitri Uzunidis studies the logic of the innovative milieu. For him, the innovative milieu is the socio-economic environment of a territory built by history and is the result of interactions among firms, institutions and human resources. These interactions stem from reciprocal synergies (networks, partnerships) between different local agents (from the 
public or the private sectors) specialized in economic and industrial development. An analysis starting from the innovative milieu provides an opportunity to study the enterprises' environment in order to understand their innovation dynamics. The systemic nature of relations which characterizes an economic and social milieu explains the incentives or the constraints to the act of innovation. Can innovation then be reduced, as a production of the milieu, to mere exchanges among individuals resulting in new productive combinations? Does innovation result from a specific organization of economic relations? Uzunidis' thesis is that the systemic nature of the milieu not only refers to economic interactions but also takes into consideration the social structures that are at the origin of innovative behaviours. In turn, the innovative milieu contributes to the firm's innovative performance, by supplying and organizing the flows of scientific and technical resources.

The contribution of Chapter 9, by Sophie Boutillier, Blandine Laperche and Dimitri Uzunidis, focuses on entrepreneurship, which can be considered to be a form of innovation. The question raised by these authors is the following: why does the entrepreneur's function, in the sense of J.A. Schumpeter, disappear? That is, why it is not long-lasting? Thanks to an approach linking economics and sociology, the construction of what the authors call his 'potential of resources' is revealed to be the set of knowledge, relations and financial resources that the entrepreneur builds in the context in which he or she acts. This potential of resources is itself not stable and may be increased or diminished, in various economic, political and social contexts. The success of entrepreneurship stems from the networks the entrepreneur creates. The formalization in terms of the 'organic square of entrepreneurship', proposed by these authors, explains the temporary character and territorial roots of the entrepreneur's function.

The next two chapters study two cases of innovative milieux and are especially focused, on the one hand, on the roles of exchange between the actors of a local system of innovation, and on the other, on the importance of the institutional structure which may boost or hinder the genesis of innovation. In Chapter 10, Kavoos Mohannak and Robyn Keast study the role of cooperative networks of high-tech SMEs within a technology park. By using a case study of an emerging South-East Queensland (Australia) technology park to provide insights, the chapter focuses on the nature of relationships and exchanges between SMEs and their stakeholders. Drawing on interviews and responses to questionnaires, including a network linkage survey and other documentary materials, this study explores the role of networks and clusters, and sheds some light on the degree of linkages between SMEs and other industry and research agents within the Brisbane Technology Park. The context and conceptual framework used for the analysis of networks within the technology park is 
centred on the relevance of two key concepts for SME development: 'innovation clusters' and 'cooperation networks', recognizing that both are emerging as significant tools to promote regional development through the activation, diffusion and expansion of locally generated knowledge.

In Chapter 11, Paul Sommers raises a significant issue: what are the differences between a clump (a mere aggregation of firms) and a cluster? Is the cluster idea a useful construct for thinking about regional development issues? To answer these questions, he uses a case study of biotechnology and life sciences in the Seattle area. The hypothesis stemming from the pattern of development of biotechnology in life sciences (rapid technological change, uncertain processes involving several institutions, importance of tacit knowledge, role of venture capital, etc.) is that clusters should be an efficient form of industry organization and that clumps should either be less successful or not present in the industry. Sommers explains public and private roles in cluster development around Seattle, notably in the creation of incentives to collaborate. Collaboration and exchanges of tacit knowledge are the key elements distinguishing a cluster from a clump, the latter being more based on competition. To conclude, Sommers presents different policy alternatives for a cluster based on research activities for the Seattle case. All (for example the development of biotechnology firms into fully integrated pharmaceutical companies, or the strengthening and the widening of the existing biotechnology cluster) require involvement by strong state and regional economic development organizations, in both short-term and long-term structural policies. To create new regional competitive advantages in the global context requires a fresh start based on existing local conditions, as well as insights about future development options for each region.

Innovation systems, whether local or national, are open systems. Their strength certainly depends on the density of their internal links, but the challenge they face also depends upon their ability to adjust to external evolutionary patterns (firms' strategic options, public policies, general economic climate). As a whole, then, the aim of this book is to reveal the role of the systemic approach to the genesis of innovation at the micro-economic level (inter-individual relations connecting knowledge production units) and at the meso-economic level that binds these together (relationships among institutions within sectors or local systems of innovation). Power relations and asymmetries, in both military and civilian spheres, have to be given full weight alongside the growing emphasis on networking and clusters. Specific lessons can then be drawn from this contribution of networks and particular innovation systems regarding global economic performance. 